\title{
Normal parathyroid function with decreased bone mineral density in treated celiac disease
}

\author{
Bernard Lemieux $\mathrm{MD}^{1}$, Michel Boivin $\mathrm{MD}^{1}$, Jean-Hugues Brossard $\mathrm{MD}^{1}$, Raymond Lepage $\mathrm{PhD}^{2}$, \\ Daniel Picard $\mathrm{MD}^{3}$, Louise Rousseau $\mathrm{BSc}^{1}$, Pierre D'Amour MD ${ }^{1}$
}

\begin{abstract}
B Lemieux, M Boivin, J-H Brossard, R Lepage, D Picard, L Rousseau, P D'Amour. Normal parathyroid function with decreased bone mineral density in treated celiac disease. Can J Gastroenterol 2001;15(5):302-307. Decreased bone mineral density (BMD) has been reported in patients with celiac disease in association with secondary hyperparathyroidism. The present study investigated whether basal parathyroid hormone (PTH) remained elevated and whether abnormalities of parathyroid function were still present in celiac disease patients treated with a gluten-free diet. Basal seric measurements of calcium and phosphate homeostasis and BMD were obtained in 17 biopsy-proven patients under treatment for a mean period of $5.7 \pm 3.7$ years (range 1.1 to 15.9). In addition, parathyroid function was studied with calcium chloride and sodium citrate infusions in seven patients. Basal measurements of patients were compared with those of 26 normal individuals, while parathyroid function results were compared with those of seven sex- and age-matched controls. Basal results were similar in patients and controls except for intact PTH (I-PTH) $(3.77 \pm 0.88 \mathrm{pmol} / \mathrm{L}$ versus $2.28 \pm 0.63 \mathrm{pmol} / \mathrm{L}, \mathrm{P}<0.001$ ), which was higher in the former group but still within normal limits. Mean 25-hydroxy vitamin D and 1,25-dihydroxy vitamin $\mathrm{D}$ values were normal in patients. Parathyroid function results were also found to be similar in both groups. Compared with a reference population of the same age (Z score), patients had significantly lower BMDs of the hip $(-0.60 \pm 0.96 \mathrm{SDs}, \mathrm{P}<0.05)$ and lumbar spine $(-0.76 \pm 1.15 \mathrm{SDs}$, $\mathrm{P}<0.05)$. T scores were also decreased for the hip $(-1.3 \pm 0.9 \mathrm{SDs}$, $\mathrm{P}<0.0001)$ and lumbar spine $(-1.4 \pm 1.35 \mathrm{SDs}, \mathrm{P}<0.0001)$, with two to three patients being osteoporotic ( $\mathrm{T}$ score less than $-2.5 \mathrm{SDs}$ ) and seven to eight osteopenic ( $\mathrm{T}$ score less than -1 SDs but greater than or equal to $-2.5 \mathrm{SDs}$ ) in at least one site.
\end{abstract}

Height and weight were the only important determinants of BMD values by multivariate or logistical regression analysis in these patients. The results show higher basal I-PTH values with normal parathyroid function in treated celiac disease. Height and weight values are, but I-PTH values are not, an important determinant of the actual bone mass of patients. Normal parathyroid function in treated patients suggests a lack of previous severe secondary hyperparathyroidism and/or complete adaptation to prior changes in parathyroid function.

Key Words: Bone mineral density measurements; Calcium; Celiac disease; Osteoporosis; Parathyroid hormone; Vitamin D

\section{Maladie coeliaque traitée, déminéralisation osseuse et fonctionnement parathyroïdien normal}

RÉSUMÉ : La documentation scientifique a déjà fait état de la diminution de la densité minérale osseuse (DMO) chez les patients atteints de la maladie coeliaque associée à une hyperthyroïdie secondaire. La présente étude vise à vérifier si le taux de parathormone $(\mathrm{PTH})$ reste élevé et si les anomalies du fonctionnement parathyroïdien persistent chez les patients dont la maladie coeliaque est traitée à l'aide d'une diète sans gluten. Des mesures sériques de base de l'homéostasie du calcium et du phosphate et de la DMO ont été prises chez 17 patients dont la maladie a été confirmée par biopsie et traitée pendant une période moyenne de $5,7 \pm 3,7$ ans (étendue de 1,1 à 15,9 ). En outre, le fonctionnement parathyroïdien a été évalué au moyen d'une perfusion à base de chlorure de calcium et de citrate de sodium chez 7 patients. Les mesures de base

voir page suivante

Centre de recherche, Centre hospitalier de l'Université de Montréal - Hôpital Saint-Luc, Départements de ${ }^{1}$ médecine, ${ }^{2}$ biochimie and ${ }^{3}$ médecine nucléaire, Université de Montréal, Montréal, Québec

Correspondence and reprints: Dr Pierre D'Amour, Centre de recherche, Centre hospitalier de l'Université de Montréal - Hôpital Saint-Luc, 302264 René Lévesque Boulevard East, Montréal, Québec H2X 1P1. Telephone 514-281-2444 ext 5704, fax 514-281-2492,

e-mail rechcalcium.chum@ssss.gouv.qc.ca

Received for publication July 20, 2000. Accepted March 9, 2001 
des patients ont été comparées à celles de 26 sujets normaux et les résultats du fonctionnement parathyroïdien, à ceux de sept témoins appariés selon l'âge et le sexe. Les résultats de base étaient de même ordre chez les patients et les sujets, sauf en ce qui concerne la PTH intacte (PTH-I ) $(3,77 \pm 0,88 \mathrm{pmol} / \mathrm{l}$ contre $2,28 \pm 0,63 \mathrm{pmol} / \mathrm{l} ; \mathrm{P}<0,001)$ dont le taux dans le premier groupe, était plus élevé mais tout de même sis dans les limites de la normale. Les valeurs moyennes de la 25 -hydroxyvitamine D et de la 1,25-dihydroxyvitamine D étaient normales chez les patients. Les résultats du fonctionnement parathyrö̈dien se sont également avérés normaux dans les deux groupes. Par contre, la DMO de la hanche $(-0,60$ $\pm 0,96$ d'écart type $[E T] ; P<0,05)$ et de la colonne lombaire $(-0,76 \pm$ $1,15 \mathrm{ET} ; \mathrm{P}<0,05)$ était significativement plus faible que celle d'une population de référence de même âge. Les scores $\mathrm{T}$ étaient également inférieurs pour la hanche $(-1,3 \pm 0,9 \mathrm{ET} ; \mathrm{P}<0,0001)$ et la colonne lom- baire $(-1,4 \pm 1,35$ ET; $\mathrm{P}<0,0001)$; deux ou trois patients étaient jugés ostéoporotiques ( $\mathrm{T} \leq-2,5 \mathrm{ET})$ et sept ou huit, ostéopéniques ( $\mathrm{T} \leq-1 \mathrm{ET}$ mais $\geq-2,5 \mathrm{ET}$ ) en au moins un point de mesure. Selon l'analyse à plusieurs variables ou l'analyse de régression logistique, la taille et le poids étaient les seuls déterminants importants de la valeur de la DMO. Somme toute, les résultats font état de taux de base de la PTH-I plus élevés que la normale chez les patients dont la maladie coeliaque est traitée, et ce, même en présence d'un fonctionnement parathyroïdien normal. La taille et le poids, contrairement à la valeur de la PTH-I, sont des déterminants importants de la masse osseuse des patients. Le fonctionnement parathyroïdien normal chez les patients traités semble indiquer l'absence d'antécédents d'une hyperthyroïdie secondaire grave ou une adaptation complète à des troubles antérieurs du fonctionnement parathyroïdien.
$\mathrm{B}$ one mineral density (BMD) is generally decreased at various sites in patients with celiac disease (1-19). A gluten-free diet with or without supplements usually improves BMD with time, but many patients retain abnormally low values characteristic of osteopenia and even osteoporosis (2,3,5-19). Decreased intestinal calcium absorption (20) leading to secondary hyperparathyroidism (17) is believed to be central to the bone loss process $(21,22)$. Mean basal parathyroid hormone (PTH) levels are slightly elevated in untreated patients $(1,9,10,13-19)$, and the response to dietary therapy varies, depending on the PTH assay used. Improved values are generally seen with intact PTH (IPTH) assays (9,13-19), and unchanged values with midcarboxylterminal assays $(1,10)$. The parathyroid function of treated patients has never been investigated even if, on a theoretical basis, a residual, increased mass of parathyroid tissue could contribute to bone abnormalities.

In a dog model of secondary hyperparathyroidism induced by dietary calcium and vitamin $\mathrm{D}$ deficiencies, a fivefold increase in parathyroid function was observed over two years (23). With treatment for another year, parathyroid function measured by I-PTH assay decreased to threefold the original value, while basal I-PTH was completely normalized because the set point of PTH stimulation by calcium was lowered (24). We investigated whether similar adaptation occurs in treated celiac disease patients to ascertain whether it could explain their bone abnormalities.

\section{SUBJECTS AND METHODS}

Experimental subjects: Seventeen patients - four men and 13 women - with intestinal biopsy-proven celiac disease were recruited from the central registry of the Centre hospitalier de l'Université de Montréal - Hôpital Saint Luc. They had been treated with a gluten-free diet since diagnosis. All of the patients agreed to participate in a basal biochemical evaluation and have their BMDs measured at the hip and lumbar spine. Only seven agreed to participate further in a study of parathyroid function. They were compared with 26 normal individuals who had participated, over the years, in various protocols on parathyroid function evaluation (25-28). These individuals were workers at the Research Centre of the Centre hospitalier de l'Université de Montréal or women recruited at the menopause clinic of the hospital. All were free of known diseases, were off medications, had a normal diet and had normal serum values of calcium, phosphate, PTH and creatinine. A subgroup of seven of these subjects, matched to the patients for age and sex, was used for parathyroid function comparison.

Experimental protocol: The experimental protocol was approved by the Human Research Ethics Committee of the Centre hospitalier de l'Université de Montréal, and all participants signed an informed consent form. The study was performed from March to June 1998, at the end of winter. Blood was obtained from each subject to measure baseline ionized calcium $\left(\mathrm{Ca}^{2+}\right)$, I-PTH, phosphate, creatinine and alkaline phosphatase. Serum 25-hydroxy vitamin D and 1,25-dihydroxy vitamin D were also measured. Parathyroid function was evaluated in seven patients. Calcium chloride and sodium citrate were infused over a $2 \mathrm{~h}$ period, as described previously (28). Each subject was studied on two different mornings, having consumed only water since the preceding evening. Each subject was seated in an armchair, and catheters were placed in both antecubital veins for infusion and blood sampling. On the first occasion, serum $\mathrm{Ca}^{2+}$ was increased for a $2 \mathrm{~h}$ period by means of an intravenous infusion of calcium chloride in $50 \mathrm{~g} / \mathrm{L}$ dextrose, which provided $125 \mu \mathrm{mol}$ elemental calcium $/ \mathrm{kg} / \mathrm{h}$. Four to seven days later, serum $\mathrm{Ca}^{2+}$ was decreased for $2 \mathrm{~h}$ by means of an intravenous infusion of sodium citrate, which provided $29 \mu \mathrm{mol} / \mathrm{kg} / \mathrm{h}$. Procaine hydrogen chloride $(12.5 \mu \mathrm{mol} / \mathrm{kg} / \mathrm{h})$ was added to the sodium citrate solution to relieve arm pain during the last infusion. Each infusion caused a $\pm 0.3 \mathrm{mmol}$ ionized calcium concentration change. Blood was sampled every 10 to $15 \mathrm{~min}$ during both infusions to measure ionized calcium and I-PTH. BMD of the hip and lumbar spine was assessed in all patients.

Biochemical measurements: Ionized calcium was measured immediately after blood collection with an $\mathrm{ICA}_{2}$ analyzer (Radiometer, Denmark); the interassay coefficients of variance were $3.3 \%$ and $2.7 \%$, respectively, at concentrations of $0.77 \mathrm{mmol} / \mathrm{L}$ and $1.75 \mathrm{mmol} / \mathrm{L}$. Serum phosphate, creatinine and alkaline phosphatase were quantified by automated colorimetry. Serum 25-hydroxy vitamin D and 1,25dihydroxy vitamin $\mathrm{D}$ were measured after extraction with acetonitrile. 1,25-dihydroxy vitamin $\mathrm{D}$ was chromatographed on C-18 and silica cartridges before quantification 
TABLE 1

Characteristics of patients with celiac disease and normal controls in the basal state (mean \pm SD)

\begin{tabular}{|c|c|c|c|c|}
\hline Parameters measured (normal range) & $\begin{array}{l}\text { Normal control } \\
\text { subjects (all) }\end{array}$ & Patients (all) & $\begin{array}{c}\text { Normal control subjects } \\
\text { (parathyroid function group) }\end{array}$ & $\begin{array}{c}\text { Patients } \\
\text { (parathyroid function group) }\end{array}$ \\
\hline$n$ & 26 & 17 & 7 & 7 \\
\hline Age (years) & $36 \pm 10$ & $50 \pm 12 *$ & $45 \pm 7$ & $45 \pm 12$ \\
\hline Weight (kg) & $65 \pm 13$ & $65 \pm 14$ & $68 \pm 14$ & $66 \pm 14$ \\
\hline Height $(\mathrm{cm})$ & - & $165 \pm 9$ & - & $170 \pm 10$ \\
\hline $\operatorname{Sex}(M: F)$ & $9: 17$ & $4: 13$ & $3: 4$ & $3: 4$ \\
\hline Ionized calcium (1.19 to $1.34 \mathrm{mmol} / \mathrm{L}$ ) & $1.23 \pm 0.03$ & $1.22 \pm 0.03$ & $1.22 \pm 0.4$ & $1.20 \pm 0.02$ \\
\hline Phospate (0.7 to $1.3 \mathrm{mmol} / \mathrm{L})$ & $0.99 \pm 0.10$ & $1.03 \pm 0.14$ & $0.97 \pm 0.06$ & $1.04 \pm 0.12$ \\
\hline Alkaline phosphotase (25 to $97 \mathrm{U} / \mathrm{L}$ ) & $52.6 \pm 21.9$ & $65 \pm 25$ & $73 \pm 34$ & $57 \pm 17$ \\
\hline Creatinine (55 to $112 \mu \mathrm{mol} / \mathrm{L}$ ) & $67 \pm 15.9$ & $66 \pm 15$ & $69 \pm 14$ & $66 \pm 21$ \\
\hline 25-hydroxy vitamin D (35 to $115 \mathrm{nmol} / \mathrm{L}$ ) & - & $66.1 \pm 35$ & - & $59.7 \pm 32.8$ \\
\hline 1,25-dihydroxy vitamin $\mathrm{D}$ (72 to $120 \mathrm{pmol} / \mathrm{L}$ ) & - & $103.4 \pm 29.6$ & - & $105.8 \pm 26.6$ \\
\hline I-PTH (1.0 to $6.8 \mathrm{pmol} / \mathrm{L})$ & $2.28 \pm 0.63$ & $3.77 \pm 0.88^{\dagger}$ & $2.53 \pm 0.68$ & $3.61 \pm 0.72^{\ddagger}$ \\
\hline
\end{tabular}

${ }^{*}$ Normal control subjects (all) versus patients (all): $P<0.01 ;{ }^{+}$Normal control subjects (all) versus patients (all): $P<0.001 ;{ }^{*}$ Normal control subjects (parathyroid function group) versus patients (parathyroid function group): $P<0.05$. I-PTH Intact parathyroid hormone

with a commercial assay (Incstar Corp, USA). The withinassay coefficient of variance for duplicate determinations was $6 \%$ for 25 -hydroxy vitamin D assay and $10 \%$ to $14 \%$ for 1,25-dihydroxy vitamin D assay. Serum PTH was measured by commercial radioimmunometric assay for intact human PTH (hPTH)-(1-84) (Allegro Intact PTH, Nichols Institute Diagnostics, USA). This assay was initially reported to react only with $\mathrm{hPTH}-(1-84)$ because available synthetic amino and carboxylterminal fragments did not react in the assay $(29,30)$. Nonetheless, this and other commercial I-PTH assays have been demonstrated to react with a molecular form of PTH other than hPTH-(1-84) in humans when sera obtained under various calcemic conditions were fractionated by high performance liquid chromatography $(31,32)$. The non-PTH-(1-84) molecular form represents approximately $20 \%$ of I-PTH in normal individuals. The reported detection limit of the assay is $0.1 \mathrm{pmol} / \mathrm{L}$ in the Nichol's Institute brochure. The intra-assay coefficient of variance for duplicates is $3.1 \%$.

BMD: BMD of the lumbar spine (L2 to L4) and right femoral neck was measured by dual-energy $\mathrm{x}$-ray absorptiometry (DXA), using a lunar DPX-IQ scanner (Lunar Corporation, USA). Measurement precision was better than $1.5 \%$ for the spine and $2.5 \%$ for the femoral neck. The results are expressed in $\mathrm{g} / \mathrm{cm}^{2}$.

Mathematical and statistical analyses: The data are presented as mean \pm SD. Biochemical comparisons between normal control subjects and patients were performed by non-paired Student's $t$ test. Standard methods were used for unvariate and multivariate or logistical regression analysis. The parathyroid function of each individual was analyzed with a mathematical model fitting the sigmoidal relationship between I-PTH and ionized calcium concentrations, as described previously $(25,28,33)$. A minimum of 15 points, derived from hypocalcemic and hypercalcemic infusions, was used for each analysis. Raw data were analyzed with the
Origin nonlinear sigmoid curve fit module (Microcal Software Inc, USA). Fitting of the calculated curve to the experimental points was evaluated by the square of the correlation coefficient $\left(\mathrm{R}^{2}\right)$. BMD is reported as absolute values $\left(\mathrm{g} / \mathrm{cm}^{2}\right), \mathrm{Z}$ scores and T scores. The $\mathrm{Z}$ score represents the number of SDs that an individual value differs from the corresponding mean normal value for sex and age, while the $\mathrm{T}$ score represents the number of SDs that an individual value differs from the peak BMD (BMD at age 20 to 40 years) of a sex-matched, normal population. World Health Organization criteria were used to define osteopenia ( $\mathrm{T}$ score less than -1 but greater than $-2.5 \mathrm{SDs}$ ) and osteoporosis ( $\mathrm{T}$ score less than $-2.5 \mathrm{SDs}$ ). The $\mathrm{Z}$ and $\mathrm{T}$ scores of patients were compared with the respective reference populations of the DXA manufacturer, using the one-sample $t$ test.

\section{RESULTS}

Clinical state: Mean patient age was $50.6 \pm 13.4$ years. The four men $(40 \pm 2$ years) were younger than the women $(54 \pm 12$ years). The mean duration of celiac disease since diagnosis was $5.7 \pm 3.7$ years and was similar in men (mean $4.8 \pm 2.2$ years; range 1.1 to 8.1 years) and women (mean $5.8 \pm 3.9$ years; range 1.1 to 15.9 years). All patients stated that they were compliant with their gluten-free diet. Their dietary response was assessed over time by repeat biopsy in the four men and eight of the women, with all of them, except one woman, having a normal or greatly improved histological picture. All 17 patients said they were clinically improved because of their diet, although reduced bowel movements, decreased abdominal cramps and weight gain were seen, usually only in the most severe cases. The direct role of gluten-free diet on specific biochemical defects was more difficult to appreciate because of simultaneous treatments with iron, folate, vitamin D and calcium. Nine women were postmenopausal, five were on hormone 


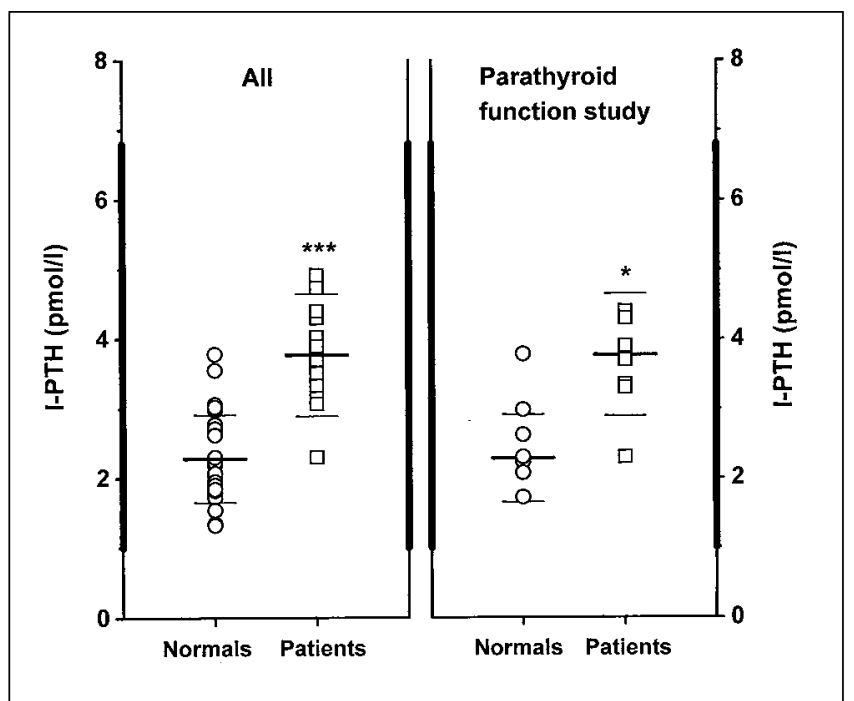

Figure 1) Levels of intact parathyroid hormone (I-PTH) in 26 normal control subjects and 17 patients with biopsy-proven celiac disease, and in seven patients and seven normal control subjects who underwent parathyroid function study. The normal range is indicated by widening of the scale

TABLE 2

Parathyroid function in patients with celiac disease and normal control subjects

\begin{tabular}{lccc}
\hline $\begin{array}{l}\text { Assay or } \\
\text { ratio }\end{array}$ & $\begin{array}{c}\text { Function } \\
\text { parameters }\end{array}$ & Normals $(\mathbf{n}=7)$ & Patients $(\mathbf{n}=7)$ \\
\hline I-PTH & Maximum & $12.6 \pm 2.1$ & $11.7 \pm 2.07$ \\
& Slope & $44.8 \pm 12.4$ & $63.4 \pm 22.3$ \\
& Set point & $1.17 \pm 0.04$ & $1.19 \pm 0.02$ \\
& Minimum & $0.75 \pm 0.26$ & $0.56 \pm 0.29$ \\
& $\mathrm{R}^{2}$ & $0.96 \pm 0.04$ & $0.95 \pm 0.04$ \\
\hline
\end{tabular}

These data are also illustrated in Figure 2. I-PTH Intact parathyroid hormone

replacement therapy, and all were consuming calcium and vitamin D supplements. Two had been taking steroids intermittently, either orally or topically, for associated vasculitis and psoriasis. As a group, the patients were older than the controls and were mostly females, but the normal control subjects, who were chosen for parathyroid function, were perfectly matched to the patients for age and sex.

Biochemical parameters and parathyroid function: The main characteristics of all normal control subjects and patients and of those who participated in the parathyroid function study are enumerated in Table 1 . The biochemical parameters were similar in the two groups except for I-PTH values, which were higher in patients but still within the normal range (Figure 1). Mean 25-hydroxy vitamin D and 1,25-dihydroxy vitamin $\mathrm{D}$ values were also normal in patients, but three of them had 25-hydroxy vitamin $D$ values below $35 \mathrm{nmol} / \mathrm{L}$, the lower limit of the normal range. Findings in the two subgroups studied for parathyroid function were similar, illustrating that the higher I-PTH levels in patients were independent of age and sex. The results of parathyroid function are presented in Table 2 and illustrated in Figure 2 as means for each group. Stimulated I-PTH (maximum), nonsuppressible I-PTH (minimum), sensitivity



Figure 2) Mean parathyroid function in normal control subjects $(-)$ and patients $(---)$ measured by an intact parathyroid hormone (I-PTH) assay

TABLE 3

Bone mineral density (BMD) measurements in patients with celiac disease

\begin{tabular}{lc}
\hline Lumbar BMD $(\mathrm{n}=17)$ & $1.04 \pm 0.16$ \\
$\mathrm{~g} / \mathrm{cm}^{2}$ & $-0.76 \pm 1.15^{*}$ \\
$\mathrm{Z}$ score (SDs) & 6 \\
$<-1>-2.5 \mathrm{SDs}$ & $-1.4 \pm 1.3^{\dagger}$ \\
$\mathrm{T}$ score $(\mathrm{SDs})$ & 3 \\
$<-2.5 \mathrm{SDs}$ & 7 \\
$<-1>-2.5 \mathrm{SDs}$ & \\
Femoral BMD $(\mathrm{n}=17)$ & $0.85 \pm 0.13$ \\
$\mathrm{~g} / \mathrm{cm}^{2}$ & $-0.60 \pm 0.96^{*}$ \\
$\mathrm{Z}$ score & 6 \\
$<-1>-2.5 \mathrm{SDs}$ & $-1.3 \pm 0.9^{\dagger}$ \\
$\mathrm{T}$ score & 2 \\
$<-2.5 \mathrm{SDs}$ & 8 \\
$<-1>-2.5$ SDs & \\
${ }^{*} P<0.05,{ }^{\dagger} P<0.001$ versus reference population measured by dual- \\
energy $x-$ ray absorptiometry
\end{tabular}

to calcium changes (slope) and set point (ionized calcium values corresponding to half-stimulation) were similar in both groups.

BMD: Table 3 presents the results of lumbar and femoral $\mathrm{BMD}$ in the 17 patients. Compared with normal individuals of the same age ( $\mathrm{Z}$ score), they had significantly lower lumbar BMD $(-0.076 \pm 1.15$ SDs, $\mathrm{P}<0.05)$ and femoral BMD $(-0.60 \pm 0.96 \mathrm{SDs}, \mathrm{P}<0.05)$. Furthermore, six individuals had values less than $-1 \mathrm{SDs}$ at each site. Compared with young normal control subjects ( $\mathrm{T}$ score), mean lumbar $\mathrm{BMD}$ $(-1.4 \pm 1.3$ SDs, $\mathrm{P}<0.001)$ and femoral BMD $(-1.3 \pm 0.9$ SDs, $\mathrm{P}<0.001$ ) were decreased by more than $1 \mathrm{SD}$ in the 17 patients. Three patients were osteoporotic (less than $-2.5 \mathrm{SDs}$ ) at the lumbar site, and two at the femoral site, while seven were osteopenic (less than -1 SDs and greater than -2.5 SDs) at the lumbar site, and eight at the femoral site. Fifty-nine per cent of the patients were either osteopenic or osteo- 
TABLE 4

Determinants of bone mineral density (BMD) in celiac disease patients treated with a gluten-free diet

\begin{tabular}{lcccc}
\hline & \multicolumn{2}{c}{ Lumbar BMD } & \multicolumn{2}{c}{ Femoral BMD } \\
Determinants & $\mathbf{R}$ & $\mathbf{P}$ & $\mathbf{R}$ & $\mathbf{P}$ \\
\hline Age (years) & -0.538 & $<0.05$ & -0.407 & 0.104 \\
Weight $(\mathrm{kg})$ & 0.664 & $<0.005$ & 0.879 & $<0.0001$ \\
Height $(\mathrm{cm})$ & 0.706 & $<0.005$ & 0.714 & $<0.001$ \\
I-PTH $(\mathrm{pmol} / \mathrm{L})$ & 0.550 & $<0.05$ & 0.177 & 0.500 \\
Creatinine $(\mathrm{mmol} / \mathrm{L})$ & 0.419 & 0.094 & 0.552 & $<0.05$ \\
Lumbar BMD & - & - & 0.641 & $<0.01$ \\
Femoral BMD & 0.641 & $<0.01$ & - & - \\
\hline
\end{tabular}

Statistical analysis by simple linear regression $(n=17)$. I-PTH Intact parathyroid hormone

porotic. Lumbar BMD (Table 4) was correlated with femoral BMD $(R=0.641, P<0.01)$, age $(R=-0.538, P<0.05)$, weight $(R=0.664, P<0.005)$, height $(R=0.706, P<0.005)$ and I-PTH $(\mathrm{R}=0.550, \mathrm{P}<0.05)$ by regression analysis. In the latter case (I-PTH), the relationship was entirely explained by three patients - two with the lowest BMD and PTH values, and one with the highest BMD and PTH values. Only height remained significant by multivariate regression analysis $(\mathrm{F}=11.4, \mathrm{P}<0.005)$. This was also true with logistical regression using lumbar $\mathrm{T}$ score less than $-1 \mathrm{SDs}$ as the threshold because height was identified as the only important covariate $\left(\mathrm{X}_{2}=6.9, \mathrm{P}<0.01\right)$. Femoral BMD (Table 4) was correlated with lumbar $\mathrm{BMD}(\mathrm{R}=0.641, \mathrm{P}<0.01)$, weight $(\mathrm{R}=0.879, \mathrm{P}<0.0001)$, height $(\mathrm{R}=0.714, \mathrm{P}<0.001)$ and creatinine $(\mathrm{R}=0.552, \mathrm{P}<0.05)$ by regression analysis. Only weight remained significant by multivariate regression analysis $(\mathrm{F}=45.9, \mathrm{P}<0.0001)$. With logistical regression analysis using the criteria previously identified, only weight remained significant $\left(\mathrm{X}_{2}=8.56, \mathrm{P}<0.005\right)$.

\section{DISCUSSION}

This study was performed to ascertain whether basal I-PTH is still elevated and parathyroid function abnormalities are still present in treated patients with celiac disease. We were interested to see whether these were important determinants of actual BMD at the hip and lumbar spine.

Basal measurements obtained in 26 normal control subjects who had participated, over the years, in parathyroid function studies (25-28) were compared with those in 17 patients with biopsy-proven celiac disease treated with a gluten-free diet for a mean period of 5.7 years. Seven of these patients who underwent a parathyroid function test were also compared with seven sex- and age-matched controls subjected to similar testing. All biochemical parameters were similar in normal individuals and patients, except for the mean I-PTH level, which was significantly higher in patients; however, individual values were still in the normal range. The normal control subjects were younger than the patients, and most of the patients were females. These differences were abolished in the seven patients and seven matched controls who had parathyroid function tests, yet mean basal I-PTH was still significantly elevated in the patients, indicating that the I-PTH results were independent of age and sex. The mean I-PTH value obtained here is very similar to the mean values of treated patients reported by several groups using the same I-PTH assay $(7,9,14,16-19)$. Most values obtained by others $(7,9,14,19)$ were also in the normal range, except in two recent studies, in which up to one-third of treated patients had values slightly above the normal range $(17,18)$. The exact reason for this is unclear, higher values being generally seen in a small proportion of untreated patients $(9,14,16,18)$ or in those refractory to treatment $(14,18)$. Eleven of the 12 patients who had a second biopsy while on treatment presented a corrected or improved histological picture and had PTH values in the normal range, while patients with elevated PTH values while on treatment demonstrated little improvement of their histological picture. This factor was not always considered in prior publications. Low 25-hydroxy vitamin D and 1,25-dihydroxy vitamin D levels have been implicated in increased mean I-PTH values $(17,18)$, but these factors were unrelated to I-PTH levels in our study. In another investigation, the proportion of low 25-hydroxy vitamin $\mathrm{D}$ values decreased from $67.8 \%$ to $7.7 \%$ over five years of dietary treatment, while high I-PTH values fell from $21.4 \%$ to $15 \%$ (19). The proportion of low 25 -hydroxy vitamin $\mathrm{D}$ values in the present study was $17.6 \%$ at the end of winter, but all I-PTH values were in the normal range. The small proportion of low 25-hydroxy vitamin $D$ values in the present study may be related to eight menopausal women who were taking calcium and vitamin D supplements. This may also have contributed to the normal I-PTH values observed here.

An analysis of parathyroid function disclosed similar functioning in patients and controls, with all four measured parameters (maximal secretory capacity, suppressible fraction of I-PTH secretion, sensitivity of PTH secretion to ionized calcium changes or slope, and the set point of I-PTH stimulation by ionized calcium) being alike in both groups. There was a nonsignificant difference of $+0.02 \mathrm{mmol} / \mathrm{L}$ ionized calcium in the set point between patients and normal control subjects. Such a difference could be sufficient, on theoretical grounds, to explain the difference in basal I-PTH concentrations between the two groups but would require much larger groups to be demonstrated experimentally. Overall, these results are reassuring because they do not disclose a residual increase in parathyroid function once the disease is treated and/or reflect a complete correction of possibly pre-existing minimal secondary hyperparathyroidism. All of the patients in the present study had basal I-PTH within the normal range, and it is possible that those with slightly elevated values, as described in other studies (16-19), could have disclosed slightly increased parathyroid function. However, even these cases are far from the severe secondary hyperparathyroidism seen in experimental models of calcium and vitamin $D$ deficiency in dogs $(23,24)$, suggesting that celiac disease is rarely associated with severe secondary hyperparathyroidism.

The BMD results in our patients were similar to those described by others in comparable studies (1-19), with 
decreased values in one-third of patients both at the lumbar spine and femoral neck compared with normals of the same age and sex ( $\mathrm{Z}$ score); 10 patients were also either osteopenic or osteoporotic ( $T$ score). Several factors, including age, height, weight and creatinine, could be related to BMD in our patients by regression analysis, but only body height or weight remained significant by multivariate or logistical regression analysis. BMD results were not adjusted for bone volume in our study, and this may have contributed to the relationship with height and weight. BMD results have not been adjusted in other studies dealing with celiac disease either (1-19). Many of these factors have been implicated in several investigations $(2,5,6,10,12,13,16)$, including time of menopause $(11,12)$. 25-hydroxy vitamin D, 1,25-dihydroxy vitamin D and I-PTH levels $(13,16-19)$ have also been implicated in some, but not all, investigations (7). The relatively small number of patients in our study may have precluded us from identifying some of these factors. Patients refractory to treatment may be important to explain the relationship between PTH and BMD $(14,17,18)$. Furthermore, time since diagnosis or duration of treatment $(2,3,5,7,10-12,15)$ is not related to BMD in patients with celiac disease. Calcium and vitamin D supplementation $(15,16)$ does not seem to influence BMD beyond the effect of diet alone.

This study confirms that BMD at the hip and lumbar spine is still reduced in celiac disease after a mean treatment period of 5.7 years. Actual basal I-PTH values and parameters of parathyroid function have minimal influence on BMD in treated patients. There is no immunoassay evidence of residual secondary hyperparathyroidism in treated patients with celiac disease.

ACKNOWLEDGEMENTS: This study was supported by grant MA-7643 from the Canadian Institutes of Health Research. The authors thank Manon Livernois for typing this manuscript, Robert Boileau for assisting in statistical analysis, and Ovid Da Silva of the Research Support Office, Research Centre of the Centre hospitalier de l'Université de Montréal, for editing the text.

\section{REFERENCES}

1. Caraceni MP, Molteni N, Bardella MT, Ortolani S, Nogara A, Bianchi PA. Bone and mineral metabolism in adult celiac disease. Am J Gastroenterol 1988;83:274-7.

2. Molteni N, Caraceni MP, Bardella MT, Ortolani S, Gandolini GG, Bianchi P. Bone mineral density in adult celiac patients and the effect of gluten-free diet from childhood. Am J Gastroenterol 1990;85:51-3.

3. Bodé S, Hassager C, Gudmand-Höyer E, Christiansen C. Body composition and calcium metabolism in adult treated coeliac disease. Gut 1991;32:1342-5.

4. Janatuinen E, Alhava E, Arnala I, et al. Bone density and histomorphometry in adult coeliac disease. Gastroenterology 1992;102:A216. (Abst)

5. Butcher GP, Banks LM, Walters JRF. Reduced bone mineral density in coeliac disease: the need for bone densitometry estimations. Gut 1992;33(Suppl 2):S54. (Abst)

6. Mora S, Weber G, Barera G, et al. Effect of gluten-free diet on bone mineral content in growing patients with celiac disease. Am J Clin Nutr 1993;57:224-8.
7. Valdimarsson T, Toss G, Ross I, Löfman O, Ström M. Bone mineral density in coeliac disease. Scand J Gastroenterol 1994;29:457-61.

8. Ciacci C, Maurelli L, Klain M, Sabbatini F, Salvatore M, Mazzacca G. Calcium homeostasis and adult celiac disease: age related recovery of bone mineral density after gluten-free diet. Gut 1994;35(Suppl 4):A197. (Abst)

9. Corazza GR, Di Sario A, Cecchetti L, Tarossi C, Jorizzo R, Gasbarrini G. Prevalence, degree and pathophysiology of bone loss in adult celiac disease. Gut 1994;35(Suppl 5):S4. (Abst)

10. Mazure R, Vazquez H, Gonzalez D, et al. Bone mineral affection in asymptomatic adult patients with celiac disease. Am J Gastroenterol 1994;89:2130-4.

11. McFarlane X, Bhalla AK, Reeves DE, Morgan LM, Robertson DAF. Osteoporosis in treated adult coeliac disease. Gut 1995;36:710-4.

12. Pistorius LR, Sweidan WH, Purdie DW, et al. Coeliac disease and bone mineral density in adult female patients. Gut 1995;37:639-42.

13. Valdimarsson T, Löfman $O$, Toss G, Ström G. Reversal of osteopenia with diet in adult coeliac disease. Gut 1996;38:322-7.

14. Keaveny AP, Freaney R, McKenna MJ, Masterson J, O’Donoghue DP. Bone remodeling indices and secondary hyperparathyroidism in celiac disease. Am J Gastroenterol 1996;91:1226-31.

15. Mautalen C, Gonzalez D, Mazure R, et al. Effect of treatment on bone mass, mineral metabolism, and body composition in untreated celiac disease patients. Am J Gastroenterol 1997;92:313-8.

16. Kemppainen T, Kröger H, Janatuinen E, et al. Osteoporosis in adult patients with celiac disease. Bone 1999;24:249-55.

17. Selby PL, Davies M, Adams JE, Mawer B. Bone loss in celiac disease is related to secondary hyperparathyroidism. J Bone Miner Res 1999;14:652-7.

18. Valdimarsson T, Toss G, Lofman O, Strom M. Three years' follow-up of bone density in adult coeliac disease: significance of secondary hyperparathyroidism. Scand J Gastroenterol 2000;35:274-80.

19. Kemppainen T, Kröger H, Janatuinen E, et al. Bone recovery after a gluten-free diet: a 5-year follow-up study. Bone 1999;25:355-60.

20. Melvin KEW, Hepner GW, Bordier P, Neale G, Joplin GF. Calcium metabolism and bone pathology in adult coeliac disease. Q J Med 1970;39:83-113.

21. Walters JRF. Bone mineral density in coeliac disease. Gut 1994;35:150-1.

22. Marsh MN. Bone disease and gluten sensitivity: time to act, to treat, and to prevent. Am J Gastroenterol 1994;89:2105-10.

23. Cloutier M, Gascon-Barré M, D'Amour P. Chronic adaptation of dog parathyroid function to a low calcium, high sodium, vitamin D deficient diet. J Bone Miner Res 1992; 7:1021-8.

24. Cloutier M, Brossard JH, Gascon-Barré M, D'Amour P. Lack of involution of hyperplastic parathyroid glands in dogs. Adaptation via a decrease in the calcium stimulation set point and a change in secretion profile. J Bone Miner Res 1994:9:621-9.

25. D’Amour P, Palardy J, Bashali G, Mallette LE, DeLéan A, Lepage R. Modulation of circulating parathyroid hormone immunoheterogeneity in man by ionized calcium concentration. J Clin Endocrinol Metab 1992;74:525-32.

26. Brossard JH, Whittom S, Lepage R, D'Amour P. Carboxyl-terminal fragments of parathyroid hormone are not secreted preferentially in primary hyperparathyroidism as they are in other hypercalcemic conditions. J Clin Endocrinol Metab 1993;77:413-9.

27. D'Amour P, Weisnagel J, Brossard JH, Ste-Marie LG, Rousseau R, Lepage R. Functional evidence for two types of parathyroid adenoma. Clin Endocrinol 1998;48:593-601.

28. Cardinal H, Brossard JH, Roy L, Lepage R, Rousseau L, D'Amour P. The set point of parathyroid stimulation by calcium is normal in progressive renal failure. J Clin Endocrinol Metab 1998;83:3839-44.

29. Nussbaum SR, Zahradnik RJ, Lavigne JR, et al. Highly sensitive two-site immunoradiometric assay of parathyrin, and its clinical utility in evaluating patients with hypercalcemia. Clin Chem 1987;33:1364-7.

30. Ratcliffe WA, Heath DA, Ryan M, Jones SR. Performance and diagnostic application of a two-site immunoradiometric assay for parathyrin in serum. Clin Chem 1989;35:1957-61.

31. Lepage R, Roy L, Brossard JH, D'Amour P. A non-(1-84) circulating parathyroid hormone (PTH) fragment interferes significantly with intact PTH commercial assay measurements in uremic samples. Clin Chem 1998;44:805-9.

32. Brossard JH, Cloutier M, Roy L, Lepage R, Gascon-Barré M, D’Amour P Accumulation of a non-(1-84) molecular form of parathyroid hormone (PTH) detected by intact PTH assay in renal failure: importance in the interpretation of PTH values. J Clin Endocrinol Metab 1996;81:3923-9.

33. Brown EM. Four-parameter model of the sigmoidal relationship between parathyroid hormone release and extracellular calcium concentration in normal and abnormal parathyroid tissue. J Clin Endocrinol Metab $1983 ; 56: 572-81$. 


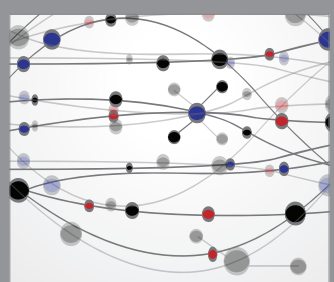

The Scientific World Journal


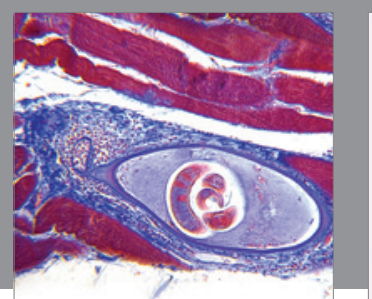

Gastroenterology Research and Practice

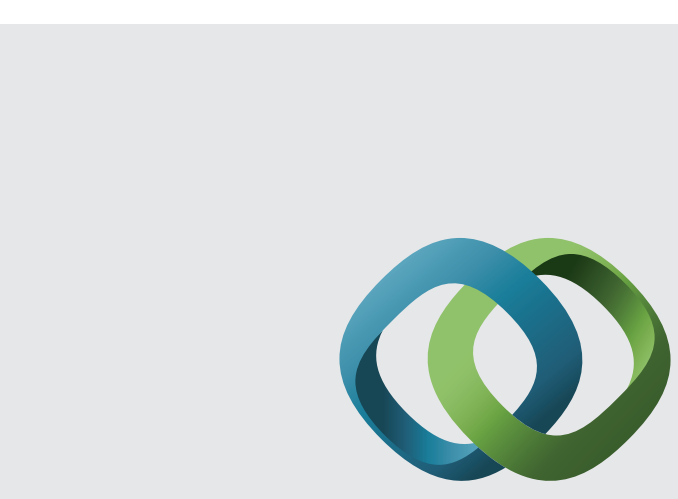

\section{Hindawi}

Submit your manuscripts at

http://www.hindawi.com

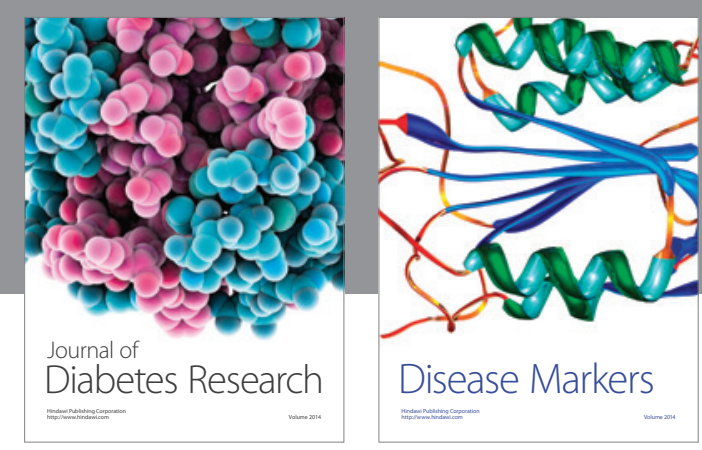

Disease Markers
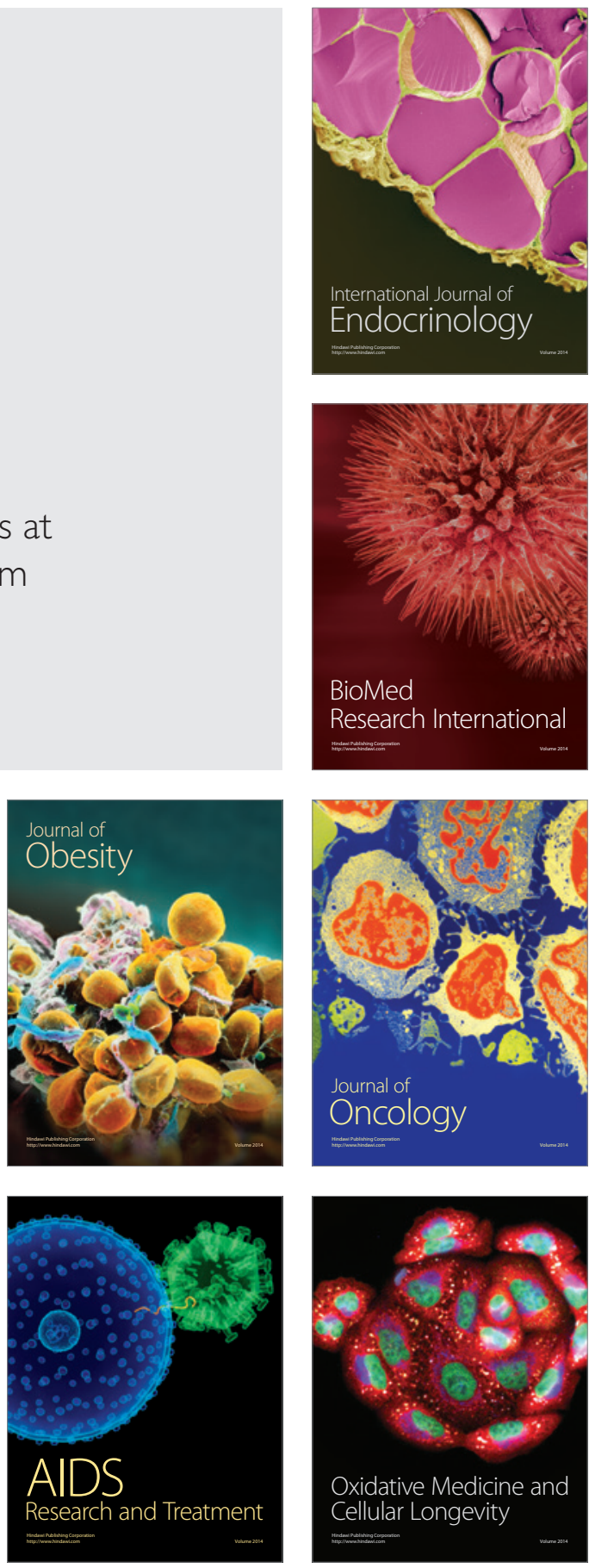